OPEN ACCESS

Edited by:

Francisco Ciruela,

University of Barcelona, Spain

Reviewed by:

Nafisa M. Jadavji,

Carleton University, Canada

Selena Bartlett,

Translational Research Institute,

Australia

*Correspondence.

Melinda Alicia Mende

mamende@uni-potsdam.de

Specialty section:

This article was submitted to Neuroenergetics, Nutrition and Brain

Health,

a section of the journal

Frontiers in Neuroscience

Received: 14 January 2019

Accepted: 24 June 2019

Published: 05 July 2019

Citation:

Mende MA (2019) Alcohol

in the Aging Brain - The Interplay

Between Alcohol Consumption,

Cognitive Decline

and the Cardiovascular System.

Front. Neurosci. 13:713.

doi: 10.3389/fnins.2019.00713

\section{Alcohol in the Aging Brain - The Interplay Between Alcohol Consumption, Cognitive Decline and the Cardiovascular System}

\author{
Melinda Alicia Mende* \\ Department of Cognitive Sciences, University of Potsdam, Potsdam, Germany
}

As our society grows older new challenges for medicine and healthcare emerge. Agerelated changes of the body have been observed in essential body functions, particularly in the loco-motor system, in the cardiovascular system and in cognitive functions concerning both brain plasticity and changes in behavior. Nutrition and lifestyle, such as nicotine intake and chronic alcohol consumption, also contribute to biological changes in the brain. This review addresses the effect of alcohol consumption on cognitive decline, changes in brain plasticity in the aging brain and on cardiovascular health in aging. Thus, studies on the interplay of chronic alcohol intake and either cognitive decline or cognitive preservation are outlined. Because of the inconsistency in the literature of whether alcohol consumption preserves cognitive functions in the aging brain or whether it accelerates cognitive decline, it is crucial to consider individual contributing factors such as culture, health and lifestyle in future studies.

Keywords: cognitive decline, neuroplasticity, AUD, alcohol consumption, aging brain

\section{INTRODUCTION}

During the lifespan, the human body and brain grow, develop and change. In early childhood, the body grows and cognitive functions develop (Dobbing and Sands, 1973), whereas in late adolescence, the human body and cognition begin to change and decline (Raz et al., 2005). Agerelated changes have been observed in essential body functions, for instance the loco-motor system, behavioral speed (Spirduso et al., 1995) and the cardiovascular system (Bender et al., 2013) as well as in cognitive processes (Raz and Rodrigue, 2006; Salthouse, 2010; Barrett and Satpute, 2013; Kennedy and Raz, 2015).

Crucially, human life expectancy has exponentially increase over the last decades. Moreover, the age in which people retire, increases as well (Galasso, 2008) forcing society to face new challenges in healthcare and acknowledge the need for a better understanding of the physical changes in late adolescence in order to develop interventions counteracting the bodily and mental decline caused by aging.

Chronic alcohol consumption is associated with a range of negative effects on the body in all age groups, for instance liver and pancreas diseases, hepatic encephalopathy, stroke, and seizures (Zahr, 2014). Regular and extensive consumption of alcohol causes white matter loss, a reduction of brain volume and neuronal loss (Mann et al., 2001). In a survey in the year 2010, the National Institutes of Health in the United States found that $28 \%$ of adults consume alcohol at such a high 
level that they are exposed to the risk for the development of alcoholism (Costin and Miles, 2014). In general, addiction is characterized by use of the drug in spite of objectively observable negative effects on social and emotional functionality and wellbeing. Drug-seeking behavior is continued by addicts regardless of legal consequences (Konova et al., 2013). Alcoholism reaches from occasional binge drinking to a fully developed alcohol use disorder (AUD). Although, AUD is not perfectly defined, the period of time and the amount of alcohol intake play an important role. Moreover, AUD is characterized by the occurrence of life problems caused by the high consumption of alcohol (Costin and Miles, 2014).

Crucially, the amount of consumed alcohol increased in older adults of the present generation compared to the previous generation (Moussa et al., 2015). On these grounds, the current review addresses general effects of negative brain changes and cognitive decline in the aging brain and the interplay with chronic alcohol consumption.

\section{CHANGES IN COGNITION AND BRAIN PLASTICITY IN THE AGING BRAIN}

\section{Changes in Cognition in the Aging Brain}

Some cognitive functions change and/or decline in aging. Nevertheless, cognitive processes are difficult to be categorized, for there are several different cognitive abilities, which contribute to one's intelligence. In the middle of last century, cognitive processes were broadly categorized into so-called fluid abilities (also called fluid intelligence) on the one hand which are crucial to find solutions for new problems by using logic and finding patterns and which decline in aging. On the other hand, crystallized abilities (also called crystallized intelligence) is the use of previously explicitly learned knowledge and is less flexible than fluid intelligence. These abilities are preserved in during the lifespan (see Cattell, 1943). More recent research has found that this distinction does not hold for all cognitive functions in aging, for instance memory, which is highly sensitive to age, even if it has been classified to be one of the crystallized functions (Buckner and Louis, 2004; Salthouse, 2010).

Yet, cognitive functions cannot be mapped to anatomical brain structures in a one-to-one relationship (Salthouse, 2010), for some cognitive processes have been detected in activation patterns that are formed by several brain areas rather than in one specific area of the brain (Barrett and Satpute, 2013). Moreover, some functional cognitive brain processes improve in aging, for instance vocabulary knowledge (Salthouse, 2010), or are generally preserved, depending on their consolidation over the lifespan (Lövdén et al., 2010). Whereas other processes, for example processing speed, rapidly decline (Salthouse, 2010).

There are two main forms of cognitive decline in aging: dementia and mild cognitive impairment (Panza et al., 2012). The latter, which is named predementia syndrome, manifests itself in nondemented decline of cognitive functions, especially in memory impairment. Nondemented means that the observed syndrome does not follow any known pattern of medical diseases, but it can turn into a form of dementia (Panza et al., 2009).
Therefore, models have been established, which aim to explain changes in brain activation as a result of changes in cognitive processes in the aging brain. Table 1 shows a summary of selected models that explain cognitive decline.

According to these models, there are cognitive mechanisms for compensating anatomical changes and reduced function of cognitive networks in the aging bran. Yet, it is not entirely clear whether more activation automatically leads to better performance in all levels of task difficulty.

\section{Changes in Brain Plasticity in the Aging Brain}

In the last decades, numerous brain imaging studies have been conducted, particularly by using functional magnetic resonance imaging, to investigate changes in activation patterns in cognitive tasks in healthy and in clinical aging (Reuter-Lorenz and Park, 2010). This methodological development widened the focus of studies on aging from psychological assessment to both a psychology and neuroscience of aging (Cabeza, 2002; Cabeza et al., 2003).

Age-related changes in cognition are caused by biological changes in the brain. Despite inter-individual differences, environmental and genetic factors, general global changes have been detected in the aging brain, in particular age-related decline in functional brain properties, i.e., cellular, molecular and also gross anatomical structures. Cross-sectional studies have revealed that the volume of prefrontal regions, the cerebellum, hippocampus and neo-striatum in aging (Kennedy and Raz, 2015). These anatomical changes in the aging brain impact the activation patterns involved in cognition. For instance, changes in white matter, atrophy of brain tissue and neurotransmitter depletion preferably occur in the fronto-striatal systems and lead to impairment of the executive functions and the memory system in advanced aging (Buckner and Louis, 2004). Nevertheless, positive changes in brain plasticity, which have been observed in younger adults, might serve as a mechanism of compensation also in the aging brain (Reuter-Lorenz and Park, 2010). Enhancing these mechanisms by treatment and training of neurocognitive functions thus is a promising method to obviate cognitive decline (Hertzog et al., 2009).

\section{INFLUENCING FACTORS ON CHANGES IN THE AGING BRAIN}

Several factors and interpersonal differences influence on brain plasticity in aging, for instance fitness (Kramer et al., 2006), health (Cesari et al., 2003), gender (Stampfer et al., 2005; Zanjani et al., 2013) and predisposition to diseases (Lipinski et al., 2010). Nutrition and lifestyle also influence biological changes in the aging brain, such as nicotine intake and chronic alcohol consumption (Beach et al., 2015). Studies on the interplay of chronic alcohol intake and changes in cognition and brain plasticity have revealed mixed results on whether it accelerates 
TABLE 1 | Models on Processes of Cognitive Decline in Healthy Aging.

\begin{tabular}{|c|c|c|c|c|c|}
\hline & Model & Brain Activation Patterns & $\begin{array}{l}\text { Modified by } \\
\text { Task Difficulty }\end{array}$ & Process & Mechanism \\
\hline A & HAROLD (Cabeza, 2002) & $\uparrow$ Hemispheric lateralization & No & $\begin{array}{l}\text { Reordering of neurocognitive } \\
\text { networks }\end{array}$ & $\begin{array}{l}\text { Compensation, } \\
\text { dedifferentiation }\end{array}$ \\
\hline B & PASA (Davis et al., 2008) & $\begin{array}{l}\downarrow \text { Occipital activation } \uparrow \\
\text { Frontal activation }\end{array}$ & No & Shift in activation & Compensation \\
\hline C & $\begin{array}{l}\text { CRUNCH (Reuter-Lorenz } \\
\text { and Cappell, 2008) }\end{array}$ & $\begin{array}{l}\uparrow \text { Frontal activation } \uparrow \\
\text { Bilateral activation (in } \\
\text { low-level cognitive tasks } \\
\text { only) }\end{array}$ & Yes & $\begin{array}{l}\text { Consumption of more } \\
\text { resources in low-level tasks }\end{array}$ & Compensation \\
\hline $\mathrm{D}$ & $\begin{array}{l}\text { STAC (Park and } \\
\text { Reuter-Lorenz, 2009) }\end{array}$ & $\begin{array}{l}\uparrow \text { Frontal activation ( } \uparrow \\
\text { Parietal, medio-temporal, } \\
\text { occipital activation) }\end{array}$ & No & Scaffolding of networks & Compensation \\
\hline
\end{tabular}

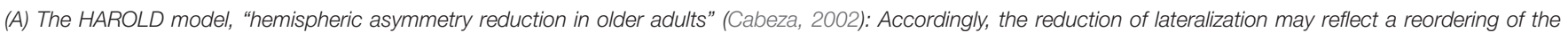

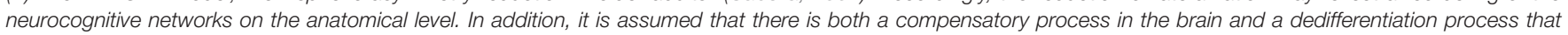

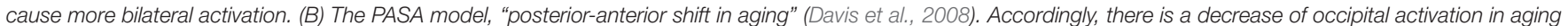

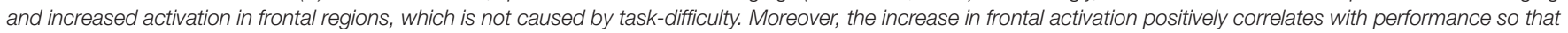

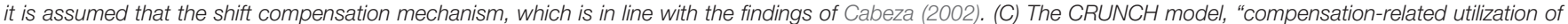

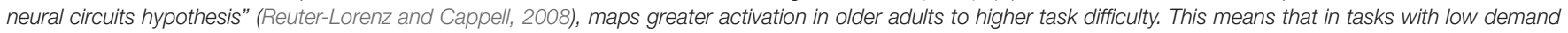

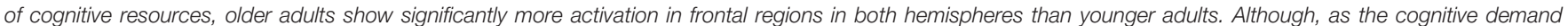

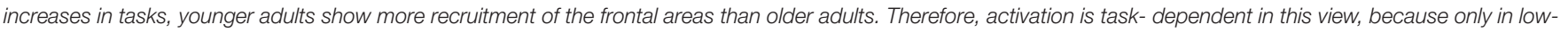

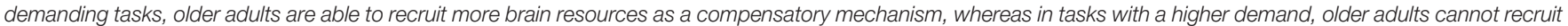

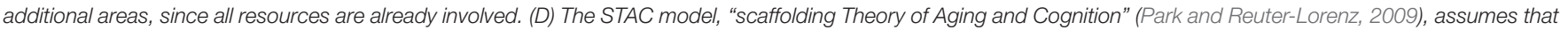

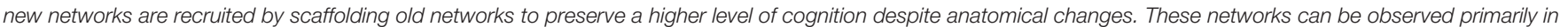

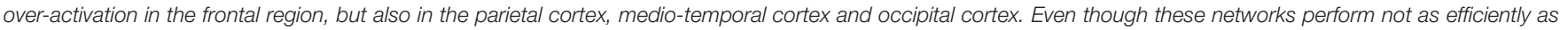
cognitive networks in younger adults, the model provides an explanation for the preservation of comparatively high cognitive abilities in older adults.

cognitive decline or preserves cognitive functions in the aging brain.

\section{Alcohol Consumption as a Factor of Cognitive Decline and Changes in Brain Plasticity General Effects of Chronic Alcohol Abuse on Brain Plasticity}

Chronic alcohol abuse is associated with changes in behavior, cognitive decline and changes in neuronal structure caused by complex neuroadaptations in the brain (Bjork and Gilman, 2014). In general, chronic alcohol consumption leads to degeneration of the spinal cord and the peripheral nervous system as well as malnutrition of brain cells due to changes in metabolism and lack of folate and thiamine (Vitamin B; Koike, 2019).

Alcohol abuse also severely affects the dopaminergic system, as repeated intake of alcohol increases the tolerance and suppresses to level of excitement, so that increasingly higher doses are consumed by addicts to stimulate their reward-system (for a review, see Burnett et al., 2016).

In addition, pharmacological tolerance and intensifying the dose of intake can lead to neuroinflammation and neural death (reviewed in Alfonso-Loeches and Guerri, 2011). The first studies that were conducted with tomographic scanning showed in vivo evidence for changes in brain plasticity in heavy drinkers (Jernigan et al., 1982; Pfefferbaum et al., 1988). Shortly after, also MRI was used to assess these changes (Pfefferbaum et al., 1992). Alcoholics and heavy drinkers have been shown to possess enlarged ventricles, whereas their overall brain volume, especially gray matter, is reduced (Kubota et al., 2001). Moreover, loss of gray matter positively correlates with years of alcohol abuse (Fein et al., 2002). In total, chronic alcohol abuse has also been found to accelerate aging-related effects (Giorgio et al., 2010). It is even possible to identify alcoholics and controls looking at MRI scans of their executive control networks and reward networks (Zhu et al., 2018). For a summary, see Table 2.

\section{In the Aging Brain}

Research has shown that chronic, heavy alcohol consumption leads to alcohol-related dementia (ARD) which is more severe than general cognitive decline in aging (Kim et al., 2012; Ridley et al., 2013; Sabia et al., 2014). ARD is a form of dementia with symptoms that are caused by alcohol intoxication and that are observable continuously, even after the alcohol intoxication has ended. The symptoms of ARD are cognitive deficit, impairment of professional life and negative impact on social relationships, similar to the symptoms of AUD. Furthermore, chronic heavy alcohol consumption leads to degeneration and demyelination of the corpus callosum in many cases, which is associated with symptoms of the Marchiafava-Bignami disease (MBD; Kim et al., 2012). The observed symptoms of MBD start with coma and contain impairments of memory function and attention, changes of the personality and malfunction of tasks which require inter-hemispheric connection and it is caused by malnutrition, particularly the lack of vitamin $\mathrm{B}$, and intoxication (Carrilho et al., 2013).

\section{Preservative Function of Alcohol Consumption in the Aging Brain}

Chronic alcohol consumption does not automatically lead to regular binge drinking or regular heavy consumption of 
TABLE 2 | Effects of Mild, Moderate and Heavy Drinking on Brain Plasticity, the Aging Brain and the Cardiovascular System.

\begin{tabular}{|c|c|c|}
\hline Imaging Method & Enlargement of $(\uparrow) /$ Decrease of $(\downarrow)$ & Correlation with \\
\hline \multicolumn{3}{|c|}{ Increase and Decrease in Brain Structures Related to Chronic Alcohol Consumption in Alcoholics Compared to Controls } \\
\hline CT (Jernigan et al., 1982) & $\uparrow$ CSF volume & Years of consumption \\
\hline CT (Pfefferbaum et al., 1988) & $\uparrow$ Sulcal volume $\uparrow$ Ventricular volume & Age ( $\uparrow$ ventricular volume) \\
\hline MRI (Pfefferbaum et al., 1992) & $\uparrow$ CSF $\downarrow$ Volume of gray and white matter & Age ( $\downarrow$ volume of gray and white matter) \\
\hline MRI (Fein et al., 2006) & $\downarrow$ Cortical gray mater volume & Age and duration of abuse \\
\hline MRI (Zhu et al., 2018) & $\begin{array}{l}\uparrow \text { Changes of structural networks (executive } \\
\text { control, reward) }\end{array}$ & - \\
\hline MRI (Zahr et al., 2019) & $\downarrow$ Hippocampal volume & Age \\
\hline Level of Consumption & $\begin{array}{l}\text { Cognitive Decline }(\downarrow) \text { / Cognitive } \\
\text { Preservation }(=) / \text { Improvement of }(\uparrow)\end{array}$ & Contributing Factors \\
\hline \multicolumn{3}{|c|}{ Effects of Chronic Alcohol Consumption on the Aging Brain } \\
\hline Heavy (Kim et al., 2012; Ridley et al., 2013) & $\downarrow:$ Alcohol-related dementia (ARD) & \\
\hline Heavy (Kim et al., 2012; Carrilho et al., 2013) & $\downarrow:$ Marchiafava-Bignami disease (MBD) & \\
\hline Mild to moderate (Moussa et al., 2015) & $=:$ Working memory, attention & \\
\hline $\begin{array}{l}\text { Mild to moderate (Bond et al., 2001; Spencer and } \\
\text { Hutchison, 1999) }\end{array}$ & $\uparrow:$ Neuroprotective effect & \\
\hline $\begin{array}{l}\text { Mild to moderate (Kim et al., 2012; Reas et al., } \\
\text { 2016) }\end{array}$ & $\uparrow:$ Prevention of cognitive decline and dementia & \\
\hline Moderate (Panza et al., 2012) & $\uparrow:$ Prevention of cognitive decline and dementia & $\begin{array}{l}\text { If no predisposition for Alzheimer's } \\
\text { disease; highest in consumption of } \\
\text { red-wine }\end{array}$ \\
\hline Level of Consumption & $\begin{array}{l}\text { Decline of }(\downarrow) \text { / Preservation of }(=) / \\
\text { Increase of }(\uparrow)\end{array}$ & Contributing Factors \\
\hline \multicolumn{3}{|c|}{ Effects of Chronic Alcohol Consumption on the Cardiovascular System } \\
\hline Heavy (Mukamal et al., 2003) & $\uparrow$ Risk of cardiovascular disease & \\
\hline Heavy (Kim et al., 2012; DiNicolantonio et al., 2018) & $\uparrow$ Damage of cardiovascular system & Malnutrition, lack of thiamine \\
\hline Mild (Kim et al., 2012) & $\downarrow$ Damage of cardiovascular system & \\
\hline Mild (Kim et al., 2012) & $\downarrow$ Risk of myocardial infarction & Most prominent in consumption of wine \\
\hline Mild (Chiva-Blanch et al., 2013) & $\downarrow$ Risk of myocardial infarction & $\begin{array}{l}\text { Most prominent in consumption of red } \\
\text { wine; associated with high } \\
\text { concentration of prophenols }\end{array}$ \\
\hline
\end{tabular}

alcohol, since besides the regularity of the consumption, the amount of alcohol intake affects the severity of cognitive damage. Many alcohol consumers consume it on a regular basis, but on a low to moderate level. For instance, Moussa et al. (2015) found no observable cognitive decline in working memory and attention of older adults, who are regularly drinkers on a low to moderate level.

Interestingly, other studies revealed that moderate alcohol consumption even provides a protection against cognitive decline in aging. Accordingly, mild to moderate consumption of alcohol is associated with a neuroprotective effect (Spencer and Hutchison, 1999; Bond et al., 2001) and therefore prevents general cognitive decline and dementia (Kim et al., 2012; Reas et al., 2016). Panza et al. (2012) identified that the preservative effects of alcohol are highest in moderate red-wine consumption and when there is no genetic predisposition for Alzheimer's Disease in the consumers. However as of now, it is not well understood which amount and regularity of alcohol intake, which genetic predispositions to diseases and which type of alcoholic beverage protects in the best manner. In addition, it is challenging to combine research findings, because methods and standards of definitions vary (Kim et al., 2012). Furthermore, influencing factors on health and cognition have not been equally assessed in previous studies and true abstainers were not distinguished from former drinkers. Therefore, Reas et al. (2016) suggested that in future research, drinking patterns, study populations and other co-varying factors should be assessed more carefully to ascertain that better cognitive performance in mild-drinkers is not accidentally caused by confounding co-variables.

\section{The Interplay of the Cardio -Vascular System, Cognitive Abilities, and Chronic Alcohol Consumption}

Studies have shown that cardiovascular risk affects cognitive performance (Bender et al., 2013), that chronic alcohol consumption affects the cardiovascular system and that higher alcohol consumption increases the risk for cardiovascular disease with decline of the fibrinolytic potential (Mukamal et al., 2003). 
Research on the interplay between cardiovascular health and cognitive decline in aging has suggested that improvements in cardiovascular health may lead to better neurocognitive functioning possibly by positively influencing brain plasticity. In particular, fluid intelligence and executive functions are assumed to be enhanced and preserved the more physically active patients are and the stronger their cardiovascular system is (Hertzog et al., 2009; Reuter-Lorenz and Park, 2010), as people who are physically more active have a general lower risk for physical diseases (Warburton et al., 2006). This is related to the positive relationship of cardiorespiratory function and cognitive abilities. In accordance, decline in pulmonary function is associated with impaired memory and attention (Ortapamuk and Aldoken, 2006). The vitamin thiamine has been found to be a key substance in this issue, since lack of thiamine is caused by chronic alcohol abuse and leads to damages of the cardiovascular system (reviewed in DiNicolantonio et al., 2018).

Similar to the finding on the effects of chronic alcohol consumption on cognition, excessive chronic consumption is associated with damage of the cardiovascular system, whereas low consumption affects the body in a cardio-protective way (Kim et al., 2012).

Another study assessed hemostatic factors, i.e., the level of fibrinogen and plasma viscosity, in a cross-sectional analysis. The authors found that low level alcohol consumption reduces the risk of myocardial infarction and cardiovascular disease, reflected by a lower level of cardiovascular health inducing factors. A separate analysis regarding the intake of different alcoholic beverages (beer, wine and liquor) showed that the cardio-protective effect was highest in winedrinkers (Mukamal et al., 2001). It thus appears that low-tomoderate consumption of wine and beer positively affects the cardiovascular system. Especially red wine has been found to be protective because of its high concentration of prophenols (Chiva-Blanch et al., 2013). Crucially, this is the opposing effect compared to malnutrition caused by chronic abuse of alcohol. Table 2 summarizes the effects of mild, moderate and heavy drinking on brain plasticity, the aging brain and the cardiovascular system.

\section{Limitations and Future Research}

Other factors highly influence alcohol tolerance. There are cultural, genetic predisposition and environmental context that contribute to differences in the amount of alcohol consumed between individuals.

Vulnerability to chronic alcohol consumption over the lifespan is modified by culture-specific custom and acceptance of drinking. For instance, Caucasians drinkers scored higher than Japanese drinkers in a cognitive test, whereas Japanese people

\section{REFERENCES}

Alfonso-Loeches, S., and Guerri, C. (2011). Molecular and behavioral aspects of the actions of alcohol on the adult and developing brain. Crit. Rev. Clin. Lab. Sci 48, 19-47. doi: 10.3109/10408363.2011.580567 had lower reaction times than Caucasians (Bond et al., 2003). Overall, so far more research has been conducted on cognitive decline and effects of alcohol consumption in Western societies than in other cultures (Park and Gutchess, 2006). Thus, more research is needed to warrant the generalizability of these results across cultures.

In addition, it is not assessed whether cultural differences in cognition are stronger in younger people (Hedden et al., 2002) or in older people (Gutchess et al., 2006). On these grounds, findings of cross-cultural studies are a promising way for gaining insights into universal biological mechanisms as well as the possibilities to influence aspects of cognitive abilities in aging (Park and Gutchess, 2006; Reuter-Lorenz and Park, 2010).

\section{CONCLUSION}

In this review, the effects of alcohol on cognitive decline in older adults were addressed. First, models for general changes in cognition in the aging brain were reviewed. In the following, it was shown that depending on the amount and frequency of consumed alcohol, the results in cognitive tests decline or improve. Whereas in heavy drinkers cognitive decline is observed, mild-to-moderate drinking might contribute a better results in cognitive tests. Similarly, cardiovascular health might be preserved by chronic intake of low amounts of alcohol, whereas high intake damages the cardiovascular system.

Future studies are needed to investigate both cognitive performance and anatomical structures with cardiovascular factors, lifestyle factors and health as co-variables.

In addition, general mechanisms of alcohol abuse lead to changes of neuroplasticity and neural circuits. The interplay between metabolism and nutrition of brain cells, loss of structures and strength of neural circuits caused by chronic alcohol intoxication provides a complicated system of interdependences. To address all these factors, future studies will benefit from machine-learning algorithms combined with brain-imaging technologies.

\section{AUTHOR CONTRIBUTIONS}

The author confirms being the sole contributor of this work and has approved it for publication.

\section{FUNDING}

I acknowledge the support of the Deutsche Forschungsgemeinschaft and Open Access Publishing Fund of University of Potsdam.

Barrett, L. F., and Satpute, A. B. (2013). Large-scale brain networks in affective and social neuroscience: towards an integrative functional architecture of the brain. Curr. Opin. Neurobiol. 23, 361-372. doi: 10.1016/j.conb.2012.12.012

Beach, S. R. H., Dogan, M. V., Lei, M. K., Cutrona, C. E., Gerrard, M., Gibbons, F. X., et al. (2015). Methylomic aging as a window onto the influence of lifestyle: 
tobacco and alcohol use alter the rate of biological aging. J. Am. Geriatr. Soc. 63, 2519-2525. doi: 10.1111/jgs.13830

Bender, A. R., Daugherty, A. M., and Raz, N. (2013). Vascular risk moderates associations between hippocampal subfield volumes and memory. J. Cogn. Neurosci. 25, 1851-1862. doi: 10.1162/jocn_a_00435

Bjork, J. M., and Gilman, J. M. (2014). The effects of acute alcohol administration on the human brain: insights from neuroimaging. Neuropharmacology 84, 101-110. doi: 10.1016/j.neuropharm.2013.07.039

Bond, G. E., Burr, R., McCurry, S. M., Graves, A. B., and Larson, E. B. (2001). Alcohol, aging, and cognitive performance in a cohort of Japanese Americans aged 65 and older: the Kame project. Int. Psychogeriatr. 13, 207-223. doi: $10.1017 / \mathrm{s} 1041610201007591$

Bond, G. E., Burr, R., Rice, M. M., McCurry, S. M., Graves, A. B., Teri, L., et al. (2003). Alcohol, aging, and cognitive performance: a cross-cultural comparison. J. Aging Health 15, 371-390. doi: 10.1177/0898264303251896

Buckner, R. L., and Louis, S. (2004). Memory and executive function review in aging and AD. Neuron 44, 195-208. doi: 10.1016/j.neuron.2004.09.006

Burnett, E. J., Chandler, L. J., and Trantham-Davidson, H. (2016). Glutamatergic plasticity and alcohol dependence-induced alterations in reward, affect and cognition. Prog. Neuropsychopharmacol. Biol. Psychiatry 65, 309-320. doi: 10. 1016/j.pnpbp.2015.08.012

Cabeza, R. (2002). Hemispheric asymmetry reduction in older adults: the HAROLD model. Psychol. Aging 17, 85-100. doi: 10.1037/0882-7974.17.1.85

Cabeza, R., Locantore, J. K., and Anderson, N. D. (2003). Lateralization of prefrontal activity during episodic memory retrieval: evidence for the production-monitoring hypothesis. J. Cogn. Neurosci. 15, 249-259. doi: 10. $1162 / 089892903321208187$

Carrilho, P. E. M., Dos Santos, M. B. M., Piasecki, L., and Jorge, A. C. (2013). Marchiafava-Bignami disease: a rare entity with a poor outcome. Rev. Bras. Ter. Intensiva 25, 68-72. doi: 10.1590/S0103-507X2013000100013

Cattell, R. B. (1943). The measurement of adult intelligence. Psychol. Bull. 40, 153-193. doi: 10.1037/10020-000

Cesari, M., Penninx, B. W., Newman, A. B., Kritchevsky, S. B., Nicklas, B. J., SuttonTyrrell, K., et al. (2003). Inflammatory markers and onset of cardiovascular events: results from the health ABC study. Circulation 108, 2317-2322. doi: 10.1161/01.CIR.0000097109.90783.FC

Chiva-Blanch, G., Arranz, S., Lamuela-Raventos, R. M., and Estruch, R. (2013). Effects of wine, alcohol and polyphenols on cardiovascular disease risk factors: evidences from human studies. Alcohol Alcohol. 48, 270-277. doi: 10.1093/ alcalc/agt007

Costin, B. N., and Miles, M. F. (2014). Molecular and neurologic responses to chronic alcohol use. Handb. Clin. Neurol. 125, 157-171. doi: 10.1016/B978-0444-62619-6.00010-0

Davis, S. W., Dennis, N. A., Daselaar, S. M., Fleck, M. S., and Cabeza, R. (2008). Qué PASA? the posterior-anterior shift in aging. Cereb. Cortex 18, 1201-1209. doi: $10.1093 /$ cercor/bhm 155

DiNicolantonio, J. J., Liu, J., and O'Keefe, J. H. (2018). Thiamine and cardiovascular disease: a literature review. Prog. Cardiovasc. Dis. 61, 27-32. doi: 10.1016/j.pcad. 2018.01.009

Dobbing, J., and Sands, J. (1973). Quantitative growth and development of human brain. Arch. Dis. Child. 48, 757-767. doi: 10.1136/adc.48.10.757

Fein, G., Di Sclafani, V., Cardenas, V. A., Goldmann, H., Tolou-Shams, M., and Meyerhoff, D. J. (2002). Cortical gray matter loss in treatment-naive alcohol dependent individuals. Alcohol. Clin. Exp. Res 26, 558-564. doi: 10.1111/j.15300277.2002.tb02574.x

Fein, G., Landman, B., Tran, H., McGillivray, S., Finn, P., Barakos, J., et al. (2006). Brain atrophy in long-term abstinent alcoholics who demonstrate impairment on a simulated gambling task. Neuroimage 32, 1465-1471. doi: 10.1016/j. neuroimage.2006.06.013

Galasso, V. (2008). Postponing retirement: the political effect of aging. J. Public Econ. 92, 2157-2169. doi: 10.1016/j.jpubeco.2008.04.012

Giorgio, A., Santelli, L., Tomassini, V., Bosnell, R., Smith, S., De Stefano, N., et al. (2010). Age-related changes in grey and white matter structure throughout adulthood. Neuroimage 51, 943-951. doi: 10.1016/j.neuroimage.2010.03.004

Gutchess, A. H., Welsh, R. C., Boduroglu, A., and Park, D. C. (2006). Cultural differences in neural function associated with object processing. Cogn. Affect. Behav. Neurosci. 6, 102-109. doi: 10.3758/CABN.6.2.102
Hedden, T., Park, D. C., Nisbett, R., Ji, L.-J., Jing, Q., and Jiao, S. (2002). Cultural variation in verbal versus spatial neuropsychological function across the life span. Neuropsychology 16, 65-73. doi: 10.1037//0894-4105.16.1.65

Hertzog, C., Kramer, A. F., Wilson, R. S., and Lindenberger, U. (2009). Enrichment effects on adult cognitive development: can the functional capacity of older adults be preserved and enhanced? Psychol. Sci. Public Interest 9, 1-65. doi: 10.1111/j.1539-6053.2009.01034.x

Jernigan, T. L., Zatz, L. M., Ahumada, A. J. Jr., Pfefferbaum, A., Tinklenberg, J. R., Moses, J. A. Jr., et al. (1982). CT measures of cerebrospinal fluid volume in alcoholics and normal volunteers. Psychiatry Res. 7, 9-17. doi: 10.1016/01651781(82)90048-8

Kennedy, K. M., and Raz, N. (2015). "Normal Aging of the Brain," in Brain Mapping: An Encyclopedic Reference, Vol. 3, ed. A. W. Toga (London: Elsevier Inc.)., doi: 10.1016/B978-0-12-397025-1.00068-3

Kim, J. W., Lee, D. Y., Lee, B. C., Jung, M. H., Kim, H., Choi, Y. S., et al. (2012). Alcohol and cognition in the elderly: a review. Psychiatry Invest. 9, 8-16. doi: 10.4306/pi.2012.9.1.8

Koike, H. (2019). "Myelopathy and Neuropathy Associated With Alcoholism," in Neuroscience of Alcohol, ed. V. R. Preedy (Cambridge, MA: Academic Press), 195-205. doi: 10.1016/B978-0-12-813125-1.00021-0

Konova, A. B., Moeller, S. J., and Goldstein, R. Z. (2013). Common and distinct neural targets of treatment: changing brain function in substance addiction. Neurosci. Biobehav. Rev. 37, 2806-2817. doi: 10.1016/j.neubiorev.2013.10.002

Kramer, A. F., Erickson, K. I., and Colcombe, S. J. (2006). Neural changes associated with training exercise, cognition, and the aging brain. J. Appl. Physiol. 101, 1237-1242. doi: 10.1152/japplphysiol.000500.2006

Kubota, M., Nakazaki, S., Hirai, S., Saeki, N., Yamaura, A., and Kusaka, T. (2001)). Alcohol consumption and frontal lobe shrinkage: study of 1432 non-alcoholic subjects. J. Neurol. Neurosurg. Psychiatry 71, 104-106. doi: 10.1136/jnnp.71.1. 104

Lipinski, M. M., Zheng, B., Lu, T., Yan, Z., Py, B. F., Ng, A., et al. (2010). Genomewide analysis reveals mechanisms modulating autophagy in normal brain aging and in Alzheimer's disease. Proc. Natl. Acad. Sci. U.S.A. 107, 14164-14169. doi: 10.1073/pnas. 1009485107

Lövdén, M., Bodammer, N. C., Kühn, S., Kaufmann, J., Schütze, H., Tempelmann, C., et al. (2010). Experience-dependent plasticity of whitematter microstructure extends into old age. Neuropsychologia 48, 3878-3883. doi: 10.1016/j.neuropsychologia.2010.08.026

Mann, K., Agartz, I., Harper, C., Shoaf, S., Rawlings, R. R., Momenan, R., et al. (2001). Neuroimaging in alcoholism: ethanol and brain damage. Alcohol. Clin. Exp. Res. 25, 104S-109S. doi: 10.1097/00000374-20010505100019

Moussa, M. N., Simpson, S. L., Mayhugh, R. E., Grata, M. E., Burdette, J. H., Porrino, L. J., et al. (2015). Long-term moderate alcohol consumption does not exacerbate age-related cognitive decline in healthy, community-dwelling older adults. Front. Aging Neurosci. 6:341. doi: 10.3389/fnagi.2014.00341

Mukamal, K. J., Conigrave, K. M., Mittleman, M. A., Camargo, C. A., Stampfer, M. J., Willett, W. C., et al. (2003). Roles of drinking pattern and type of alchohol consumed in coronary heart disease in men. N. Engl. J. Med. 348, 109-118. doi: 10.1056/NEJMoa022095

Mukamal, K. J., Jadhav, P. P., D’Agostino, R. B., Massaro, J. M., Mittleman, M. A., Lipinska, I., et al. (2001). Alcohol consumption and hemostatic factors: analysis of the Framingham Offspring cohort. Circulation 104, 1367-1373. doi: 10.1161/ hc3701.096067

Ortapamuk, H., and Aldoken, S. (2006). Brain perfusion abnormalities in chronic obstructive pulmonary disease: comparison with cognitive impairment. Ann. Nucl. Med. 20, 99-106. doi: 10.1007/bf02985621

Panza, F., Capurso, C., D’Introno, A., Colacicco, A. M., Frisardi, V., Lorusso, M., et al. (2009). Alcohol drinking, cognitive functions in older age, predementia, and dementia syndromes. J. Alzheimer's Dis. 17, 7-31. doi: 10.3233/JAD-20091009

Panza, F., Frisardi, V., Seripa, D., Logroscino, G., Santamato, A., Imbimbo, B. P., et al. (2012). Alcohol consumption in mild cognitive impairment and dementia: harmful or neuroprotective? Int. J. Geriatr. Psychiatry 27, 1218-1238. doi: 10. 1002/gps.3772

Park, D., and Gutchess, A. (2006). The cognitive neuroscience of aging. Current Directions in Psychological Science 15, 105-108. 
Park, D. C., and Reuter-Lorenz, P. A. (2009). The adaptive brain: aging and neurocognitive scaffolding. Annu. Rev. Psychol. 60, 173-196. doi: 10.1146/ annurev.psych.59.103006.093656

Pfefferbaum, A., Lim, K. O., Zipursky, R. B., Mathalon, D. H., Rosenbloom, M. J., Lane, B., et al. (1992). Brain gray and white matter volume loss accelerates with aging in chronic alcoholics: a quantitative MRI study. Alcohol Clin.Exp. Res. 16, 1078-1089. doi: 10.1111/j.1530-0277.1992.tb00702.x

Pfefferbaum, A., Rosenbloom, M., Crusan, K., and Jernigan, T. L. (1988). Brain CT changes in alcoholics: effects of age, and alcohol consumption. Alcohol. Clin. Exp. Res. 12, 81-87. doi: 10. (1111)/j.1530-0277.1988.tb00137.x

Raz, N., Lindenberger, U., Rodrigue, K. M., Kennedy, K. M., Head, D., Williamson, A., et al. (2005). Regional brain changes in aging healthy adults: general trends, individual differences and modifiers. Cereb. Cortex 15, 1676-1689. doi: 10.1093/ cercor/bhi044

Raz, N., and Rodrigue, K. M. (2006). Differential aging of the brain: patterns, cognitive correlates and modifiers. Neurosci. Biobehav. Rev. 30, 730-748. doi: 10.1016/j.neubiorev.2006.07.001

Reas, E. T., Laughlin, G. A., Kritz-Silverstein, D., Berrett-Connor, E., and McEvoy, L. K. (2016). Moderate, regular alcohol consumption is associated with higher cognitive function in older, community-dwlling adults. J. Prev. Alzheimer's Dis. 3, 105-113.

Reuter-Lorenz, P. A., and Cappell, K. A. (2008). Neurocognitive ageing and the Compensation Hypothesis. Curr. Dir. Psychol. Sci. 17, 177-182. doi: 10.1111/j. 1467-8721.2008.00570.x

Reuter-Lorenz, P. A., and Park, D. C. (2010). Human neuroscience and the aging mind: a new look at old problems. J. Gerontol. B Psychol. Sci. Soc. Sci. 64, 405-415. doi: 10.1093/geronb/gbq035

Ridley, N. J., Draper, B., and Withall, A. (2013). Alcohol-related dementia: an update of the evidence. Alzheimer's Res. Ther. 5:3. doi: 10.1186/alzrt157

Sabia, S., Elbaz, A., Britton, A., Bell, S., Dugravot, A., Shipley, M., et al. (2014). Alcohol consumption and cognitive decline in early old age. Neurology 82, 332-339. doi: 10.1212/WNL.0000000000000063

Salthouse, T. A. (2010). Selective review of cognitive aging. J. Int. Neuropsychol. Soc. 16, 754-760. doi: 10.1017/S1355617710000706
Spencer, R. L., and Hutchison, K. E. (1999). Alcohol, aging, and the stress response. Alcohol Res. Health? 23, 272-283.

Spirduso, W., Francis, K., and MacRae, P. (1995). Physical Dimensions of Aging. Champaign, IL: Human Kinetics.

Stampfer, M. J., Kang, J. H., Chen, J., Cherry, R., and Grodstein, F. (2005). Effects of moderate alcohol consumption on cognitive function in women. N. Engl. J. Med. 352, 245-253. doi: 10.1056/nejmoa041152

Warburton, D. E. R., Nicol, C. W., and Bredin, S. S. D. (2006). Health benefits of physical activity: the evidence. Can. Med. Assoc. J. 174, 801-809. doi: 10.1503/ cmaj.051351

Zahr, N. M. (2014). Structural and microstructral imaging of the brain in alcohol use disorders. Handb. Clin. Neurol. 125, 275-290. doi: 10.1016/B978-0-44462619-6.00017-3

Zahr, N. M., Pohl, K. M., Saranathan, M., Sullivan, E. V., and Pfefferbaum, A. (2019). Hippocampal subfield CA2 +3 exhibits accelerated aging in alcohol use disorder: a preliminary study. NeuroImage Clin. 22:101764. doi: 10.1016/j.nicl. 2019.101764

Zanjani, F., Downer, B. G., Kruger, T. M., Willis, S. L., and Schaie, K. W. (2013). Alcohol effects on cognitive change in middle-aged and older adults. Aging Ment Health 17, 12-23. doi: 10.1080/13607863.2012.717254

Zhu, X., Du, X., Kerich, M., Lohoff, F. W., and Momenan, R. (2018). Random forest based classification of alcohol dependence patients and healthy controls using resting state MRI. Neurosci. Lett. 676, 27-33. doi: 10.1016/j.neulet.2018.04.007

Conflict of Interest Statement: The author declares that the research was conducted in the absence of any commercial or financial relationships that could be construed as a potential conflict of interest.

Copyright (c) 2019 Mende. This is an open-access article distributed under the terms of the Creative Commons Attribution License (CC BY). The use, distribution or reproduction in other forums is permitted, provided the original author(s) and the copyright owner(s) are credited and that the original publication in this journal is cited, in accordance with accepted academic practice. No use, distribution or reproduction is permitted which does not comply with these terms. 